\title{
Timotein (Phleum pratense L.) eri versotyyppien vaikutus sadon määrän ja sulavuuden kehitykseen
}

\author{
Kirsi Pakarinen ${ }^{1)}$, Perttu Virkajärvi ${ }^{1)}$, Mervi Seppänen ${ }^{2)}$ ja Marketta Rinne ${ }^{3)}$ \\ ${ }^{1)}$ MTT Kotieläintuotannon tutkimus, Maidon ja naudanlihan tutkimus, Halolantie 31 A, 71750 \\ Maaninka. kirsi.pakarinen@mtt.fi,perttu.virkajarvi@mtt.fi \\ ${ }^{2)}$ Helsingin yliopisto, Soveltavan biologian laitos, Latokartanonkaari 9, 00014 Helsingin yliopisto, \\ mervi.seppanen@helsinki.fi \\ ${ }^{3)}$ MTT Kotieläintuotannon tutkimus, Maidon ja naudanlihan tutkimus, H-talo, 31600 Jokioinen, \\ marketta.rinne@mtt.fi
}

\section{Tiivistelmä}

Timotein (Phleum pratense L.) pää- ja jälkisadosta voidaan erottaa kolme erilaista versotyyppiä (vegetatiivinen, vegetatiivinen elongoituva ja generatiivinen), mutta niiden yksilöllisestä sulavuudesta tai osuudesta nurmikasvustossa tiedetään varsin vähän. Näiden eri versotyyppien esiintymistä ja rehuarvoa säilörehunurmen pää- ja jälkisadon kehityksen eri vaiheissa tutkittiin vuosina 2006 - 2007 Maa- ja elintarviketalouden tutkimuskeskuksen Maaningan tutkimusasemalla suoritetussa kokeessa. Koe suoritettiin kolmena kerranteena Tammisto II-lajikkeella.

Pääsadon niitot suoritettiin kolmella eri kehitysasteella (varhainen, keskimääräinen ja myöhäinen säilörehun tekoajankohta) viikon välein ja jälkisadon niitot 4,6 ja 8 viikkoa keskimääräisen pääsadon korjuun jälkeen. Ennen jokaista niittokertaa koeruutujen kasvustosta otettiin näytekehikolla osanäytteet, jotka eroteltiin silmämääräisesti korren solmujen ja kukintojen olemassaolon perusteella vegetatiiviseen, vegetatiiviseen elongoituvaan ja generatiiviseen versotyyppiin sekä irralliseen elävään ja irralliseen kuolleeseen materiaaliin sekä muihin lajeihin. Kustakin versotyypistä eroteltiin edelleen elävä lehtilapa, lehtitupen sisältävä korsi, kukinto ja versoon kiinnittynyt kuollut solukko omiksi fraktioikseen. Jokaisesta saadusta timoteifraktiosta määritettiin kuiva-ainemassa ja rehuarvot. Kunkin versotyypin kuiva-ainemassa ja rehuarvo laskettiin siihen kuuluvien fraktioiden tulosten perusteella.

Aikaisemmin tunnettujen vegetatiivisen ja generatiivisen versotyypin lisäksi timoteikasvustosta voitiin erottaa vegetatiivinen elongoituva versotyyppi, joka tuottaa aitokortta, mutta ei lainkaan kukintoa. Sen osuus kasvustosta oli merkittävä erityisesti jälkisadossa kasvuston myöhäisemmillä kehitysasteilla, jolloin jälkisadon säilörehua tavallisesti tehdään.

Koko kasvuston lehtien massaosuus (elävän lehtisolukon osuus kokonaiskuiva-aineesta) selitti hyvin muutoksia pääsadon D-arvossa, mutta ei jälkisadossa. Vegetatiivisten versojen D-arvo pysyi hyvänä pää- ja jälkisadossa. Tämä johtui mahdollisesti niiden korkeasta lehtien massaosuudesta, vaikka lehtien massaosuuden muutosten ei kuitenkaan havaittu korreloivan niiden D-arvon muutoksen kanssa. Vegetatiivisten elongoituvien versojen lehtien massaosuus oli sekä pää- että jälkisadossa korkeampi kuin generatiivisten versojen. Vegetatiivisen elongoituvan ja generatiivisen versotyypin lehtien massaosuuden muutoksen ja D-arvon muutoksen välillä havaittiin positiivinen korrelaatio pääsadossa.

Vegetatiivisten elongoituvien versojen ja generatiivisten versojen D-arvo näytti olevan pääsadossa samalla tasolla, mutta jälkisadossa vegetatiivinen elongoituva versotyyppi oli selvästi generatiivista sulavampi. Jälkisadon vegetatiivisen elongoituvan versotyypin parempi sulavuus voi selittyä sen aitokorren korkeammalla sulavuudella, sillä näiden versotyyppien elävän lehden tai versoihin kiinnittyneen kuolleen solukon sulavuuksissa ei havaittu merkittäviä eroja.

Asiasanat: timotei, säilörehu, versotyyppi, pääsato, jälkisato, D-arvo, lehtien massaosuus 


\section{Johdanto}

Timotei (Phleum pratense L.) on Skandinavian eniten viljelty monivuotinen heinäkasvi, ja se on yleinen myös muilla viileän ilmastovyöhykkeen alueilla Euroopassa, Aasiassa ja Pohjois-Amerikassa (Bélanger 2006). Suomessa timoteinurmia käytetään säilörehuntuotantoon, laitumeksi ja kuivaheinän tuotantoon. Säilörehua tuotettaessa timoteinurmista saadaan koko Suomessa kaksi tai kolme satoa kasvukaudessa. Jokaisella sadonkorjuukerralla on tavoitteena saada korkea satomäärä ruokinnalliselta arvoltaan hyvälaatuista rehua. Nurmikasvuston rehuarvoa voidaan parhaiten kuvata kasvuston sulavuudella, esimerkiksi D-arvolla (sulavan orgaanisen aineen pitoisuus kuiva-aineessa, $\mathrm{g} \mathrm{kg}^{-1} \mathrm{ka}$ ), tai kuitujen sulavuudella, esimerkiksi sulamattoman neutraalidetergenttikuidun pitoisuudella kuivaaineessa (Rinne 2000, Huhtanen ym. 2006).

Pääsadon (kasvukaudella kehittyvä ensimmäinen sato) kehittyessä satomäärä kohoaa, mutta samaan aikaan sulavuus heikkenee. Kun pääsadon timotei-nurminata-nurmien satomäärä kohoaa noin $150 \mathrm{~kg} \mathrm{ha}^{-1} \mathrm{ka} \mathrm{vrk}^{-1}$, on D-arvon havaittu laskevan samaan aikaan noin $5 \mathrm{~g} \mathrm{~kg}^{-1} \mathrm{ka} \mathrm{vrk}^{-1}$ vauhdilla kiivaimman kasvustonkehityksen aikana. Huolimatta korkeasta lehtipitoisuudestaan jälkisadon sulavuus on tyypillisesti pääsatoa heikompi, eikä sen maidontuotantovaikutuksen arviointi ei ole yksinkertaista. (Kuoppala ym. 2007.) Säilörehunurmen pääsadon rehuarvon kehitysrytmi tunnetaan jo kohtuullisella tarkkuudella keskimääräisen korjuuajan ennustamiseksi, mutta jälkisadon kehityksen ennustaminen on osoittautunut haasteelliseksi. Puhtaiden timoteikasvustojen rehuarvon kehitystä tunnetaan vielä tätäkin heikommin.

Koska nurmikasvusto koostuu yksittäisistä versoista, kasvustossa tapahtuvat muutokset ovat riippuvaisia versokohtaisista muutoksista. Kunkin sadon kehityksen alussa kasvusto koostuu vegetatiivisista (VEG) eli ei kukintoa tai aitokortta tuottavista versoista, ja riittävän induktion jälkeen osa versoista virittyy kukintaan ja erilaistuu generatiivisiksi (GEN) versoiksi. Solmuvälin pitenemisen, sen jälkeisen aitokorren muodostumisen ja lehtien massaosuuden (elävän lehtisolukon osuus kokonaiskuiva-aineesta, LWR) vähenemisen on ajateltu seuraavan kukintaan virittymistä. Timoteikasvustoista on kuitenkin löydetty kolmattakin versotyyppiä edustavia versoja; vegetatiivisia elongoituvia (ELONG) versoja, jotka tuottavat aitokortta, mutta eivät kukintoa (Höglind ym. 2005). Tähän saakka timotein eri versotyyppien rehuarvot ja osuudet kasvustossa sen eri kehitysvaiheissa ovat olleet huonosti tunnettuja.

Tämän tutkimuksen tavoite oli selvittää timoteikasvustossa esiintyvien kolmen erilaisen versotyypin osuuksia ja rehuarvoja kasvustonkehityksen eri vaiheissa sekä pääsadon että jälkisadon aikana. Samalla haluttiin tutkia eri kasvinosien osuuden ja rehuarvon muutoksia eri versotyypeissä sekä timoteikasvustossa esiintyvän kuolleen solukon määrää ja rehuarvoa kasvuston varttuessa. Erityisesti haluttiin selvittää näiden tekijöiden merkitystä satomäärän ja rehuarvon kehitykseen.

\section{Aineisto ja menetelmät}

Koe suoritettiin Maa- ja elintarviketalouden tutkimuskeskuksen Maaningan tutkimusasemalla vuosina 2006 - 2007. Kenttäkoe perustettiin vuonna 2005 kolmena kerranteena käyttäen 14,6 kg ha-1 Tammisto II-timoteitä ja ohraa (Kunnari) suojakasvina. Suojavilja niitettiin elokuussa tähkälletulon jälkeen. Nurmivuosina 2006 ja 2007 koeruudut saivat keväällä $450 \mathrm{~kg} \mathrm{ha}^{-1}$ Nurmen Y-lannosta ja pääsadon niiton jälkeen $450 \mathrm{~kg} \mathrm{ha}^{-1}$ Nurmen NK1-lannosta, joissa pääsadolle annettiin $90 \mathrm{~N}-13,5 \mathrm{P}-$ $22,5 \mathrm{~K}$ ja jälkisadolle $90 \mathrm{~N}-0 \mathrm{P}-31,5 \mathrm{~K}$. Koeruudut oli jaettu osaruutuihin siten, että sekä pää- että jälkisadosta oli mahdollista suorittaa kolme niittoa kasvuston eri kehitysvaiheissa.

Pääsadon niittojen aloitusajankohtaa pyrittiin ennakoimaan Artturi-korjuuaikatiedotuksen (www.mtt.fi/artturi) ja kasvuston silmämääräisen kehitysasteen perusteella. Niitot tehtiin $7 \mathrm{~cm}$ sänkikorkeuteen ja niiton yhteydessä määritettiin kuiva-aineen kokonaissato ( $\mathrm{kg} \mathrm{ka} \mathrm{ha}^{-1}$ ). Pääsadon niitot pyrittiin ajoittamaan säilörehunteon kannalta kasvuston aikaiseen (PS1), keskimääräiseen (PS2) ja myöhäiseen (PS3) kehitysvaiheeseen 7 vrk välein. Keskimääräiseksi arvioituna pääsadon niittoajankohtana niitettiin myös jälkisadon niittoja varten tarkoitetut koeruudut, joilta suoritettiin jälkisadon niitot 4, 6 ja 8 viikkoa (niitot JS1, JS2 ja JS3) pääsadon niiton jälkeen.

Jokaisena niittoajankohtana koeruuduista otettiin näytekehikolla osanäyte leikkaamalla kasvusto $0 \mathrm{~cm}$ sänkikorkeuteen. Näyte eroteltiin ensin eri versotyyppeihin (VEG, ELONG ja GEN sisältäen myös osittain tai kokonaan kuolleet versot), irralliseen elävään ja irralliseen kuolleeseen timoteimateriaaliin sekä muihin lajeihin. Versoluokittelu tehtiin seuraavasti: 1) VEG: ei aitokortta vaan pseudokorsi, ei näkyviä tai tunnustelemalla havaittavia solmuja; 2) ELONG: aitokorsi, jossa 
vähintään yksi näkyvä tai tunnusteltaessa havaittava solmu, mutta ei näkyvää tai lehtitupessa tuntuvaa kehittyvää kukintoa; 3) GEN: aitokorsi, jossa solmuja ja näkyvä tai lehtitupessa tuntuva kukinto. Versotyypit eroteltiin edelleen korteen (sisältäen pseudokorren ja lehtitupet), elävään lehtilapaan, kukintoon ja versoon kiinnittyneeseen kuolleeseen solukkoon. Kaikki fraktiot kuivattiin $+60{ }^{\circ} \mathrm{C}: \mathrm{ssa} 40$ $\mathrm{h}$ ja niiden kuiva-ainemassat määritettiin. Fraktioiden orgaanisen aineen sulavuus määritettiin pepsiinisellulaasimenetelmällä (Nousiainen ym. 2003) ja tuhkapitoisuus tuhkaamalla näytteet $+600{ }^{\circ} \mathrm{C}$ :ssa $12 \mathrm{~h}$ (vuonna 2006) tai $2 \mathrm{~h}$ (vuonna 2007). Fraktioiden in vitro D-arvot $\left(\mathrm{g} \mathrm{kg}^{-1} \mathrm{ka}\right.$ ) määritettiin sellulaasisulavuuden ja tuhkapitoisuuden perusteella $(\mathrm{D}$-arvo $=$ orgaanisen aineen sulavuus $\times$ orgaanisen aineen pitoisuus). Eri versotyyppien tuottamat kuiva-ainemassat ja niiden rehuarvot laskettiin kuhunkin versotyyppiin kuuluvista fraktioista saatujen osuus- ja rehuarvotulosten perusteella.

Tulokset analysoitiin varianssianalyysillä (ANOVA) käyttäen SAS:n (versio 9.1) Mixed Modelproseduuria. Kunkin versotyypin tulokset yhdistettiin pää- ja jälkisadon sisällä, mutta vuodet analysoitiin erikseen. Data oli epätasapainoinen siitä biologisesta syystä, että kaikkia versotyyppejä ei esiintynyt kaikissa niittoajankohdissa, joten varhaisten kehitysasteiden niitot PS1 ja JS1 jätettiin pois lopullisesta analyysistä. Pääasiallisen mielenkiinnon kohteena oli ELONG- ja GEN-versotyyppien Darvojen vertailu, joka suoritettiin analysoimalla nämä versotyypit erikseen. Satokerran (pääsato tai jälkisato) ja versotyypin yhdysvaikutus oli tilastollisesti merkittävä $(P<0,012)$, joten lopulta data analysoitiin satokerroittain ja vuosittain. D-arvon ja nurmen muiden ominaisuuksien välisiä suhteita analysoitiin korrelaatioanalyysillä.

\section{Tulokset ja tulosten tarkastelu}

VEG-versotyypin sadontuottokyky ( $\mathrm{kg} \mathrm{ka} \mathrm{ha}^{-1}$ ) oli varsin heikko pääsadossa molempina vuosina, mutta erityisesti jälkisadon kehityksen alussa se pystyi tuottamaan huomattavan määrän satoa. ELONG-versotyyppi puolestaan tuotti merkittäviä määriä kuiva-ainetta sekä pää- että jälkisadossa. Jälkisadon kahdessa myöhäisemmässä niitossa se tuotti suurimman osan koko nurmikasvisadosta. GEN-versotyyppi tuotti suurimman osan pääsadon kuiva-aineesta, mutta jälkisadossa GEN-versojen osuus sadosta oli pieni. (Kuva 1.) Versotyyppien muodostaman nurmimassan lisäksi kokonaissatoon sisältyi huomattava määrä irrallista kuollutta timoteimateriaalia; vuonna 2006 sitä oli pääsadossa 473 ja jälkisadossa $639 \mathrm{~kg} \mathrm{ka} \mathrm{ha}^{-1}$, sekä vuonna 2007 vastaavasti 522 ja 397 kg ka ha ${ }^{-1}$.

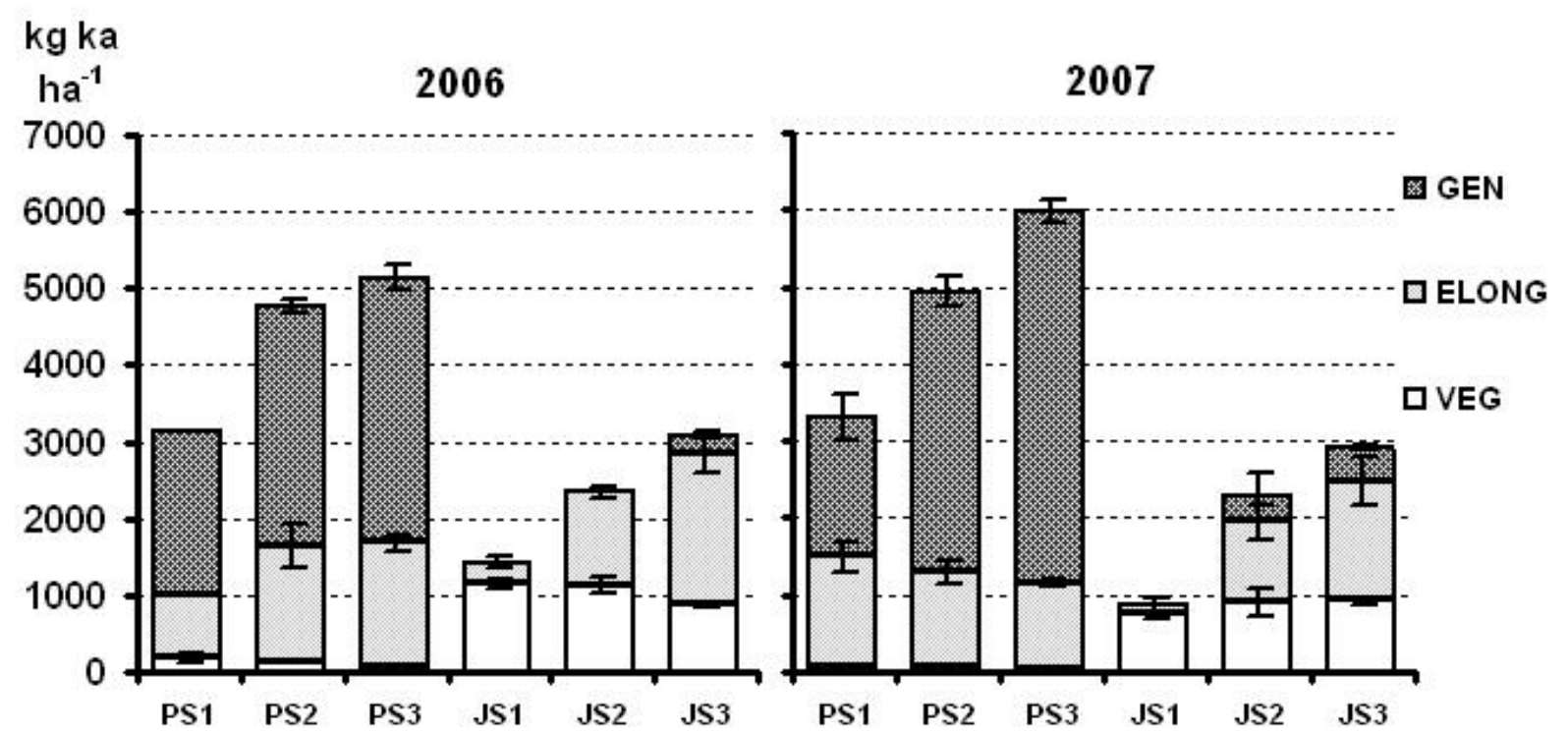

Kuva 1. Timotein vegetatiivisen (VEG), vegetatiivisen elongoituvan (ELONG) ja generatiivisen (GEN) versotyypin tuottamat kuiva-ainesadot $\left(\mathrm{kg} \mathrm{ka} \mathrm{ha}^{-1}\right)$ pääsadon (PS1 - PS3) ja jälkisadon (JS1 - JS3) kehittyessä vuosina 2006 ja 2007. N = 3. Irrallisen kuolleen timoteimateriaalin määrää ei ole esitetty.

VEG-versojen D-arvo pysyi melko vakiona sekä niittojen että vuosien välillä ollen $678-697 \mathrm{~g} \mathrm{~kg}^{-1} \mathrm{ka}^{-1}$ pääsadossa ja 673 - $714 \mathrm{~g} \mathrm{~kg}^{-1} \mathrm{ka}$ jälkisadossa. Tämä vaikuttaa loogiselta, sillä VEG-versot koostuvat lähinnä lehdestä ja lehtitupista ja niiden LWR on korkea. VEG-versoihin ei myöskään muodostu 
aitokortta kuten muihin versotyyppeihin. Niinpä aitokorrellisten ELONG- ja GEN-versotyyppien D-arvojen vertailu vaikutti mielenkiintoisemmalta. Näiden versotyyppien D-arvot olivat samankaltaisia pääsadossa, mutta jälkisadossa ELONG-versojen D-arvo oli $38-40 \mathrm{~g} \mathrm{~kg}^{-1} \mathrm{ka}$ korkeampi kuin GEN-versojen. (Taulukko 1.) Nurmikasvustossa runsaina määrinä esiintyneen irrallisen kuolleen materiaalin sulavuus oli erittäin heikko, sillä pääsadossa sen D-arvo oli $589 \mathrm{~g} \mathrm{~kg}^{-1} \mathrm{ka}\left(\mathrm{SD} \pm 1,9 \mathrm{~g} \mathrm{~kg}^{-1} \mathrm{ka}\right)$ ja jälkisadossa $\left.492 \mathrm{~g} \mathrm{~kg}^{-1} \mathrm{ka} \pm 1,4\right)$. Irrallisen kuolleen materiaalin vaikutus koko nurmikasvisadon sulavuuteen voi siis olla merkittävä.

Taulukko 1. Timotein aitokorrellisten versotyyppien (vegetatiivinen elongoituva, ELONG ja generatiivinen, GEN) D-arvo ( $\mathrm{g} \mathrm{kg}^{-1} \mathrm{ka}$ ) ja lehtien massaosuus (LWR) pääsadossa ja jälkisadossa vuosina 2006 ja 2007. Arvot ovat kahden perättäisen niittoajankohdan keskiarvoja (pääsadossa keskimääräinen ja myöhäinen niittoajankohta, jälkisadossa niitot 6 ja 8 viikkoa pääsadon korjuun jälkeen). $\mathrm{N}=6$, niittoajankohdan vaikutus $\mathrm{P}<0,05$ jokaisessa tapauksessa.

\begin{tabular}{|l|l|l|l|l|l|l|l|l|l|}
\hline & & \multicolumn{9}{|c|}{2006} & \multicolumn{4}{c|}{ 2007 } \\
\hline & & ELONG & GEN & SEM & \multicolumn{1}{|c|}{} & ELONG & GEN & SEM & P \\
\hline D-arvo & Pääsato & 640 & $636^{\text {a }}$ & 1,4 & 0,15 & 671 & $665^{\text {a }}$ & 7,6 & 0,33 \\
\hline & Jälkisato & 723 & 683 & 3,3 & $0,01^{*}$ & 669 & 631 & 5,4 & $0,015^{*}$ \\
\hline LWR & Pääsato & 0,33 & 0,18 & 0,010 & $0,002^{* *}$ & 0,41 & 0,16 & 0,018 & $0,011^{*}$ \\
\hline & Jälkisato & 0,32 & 0,20 & 0,012 & $0,011^{*}$ & 0,42 & 0,20 & 0,025 & $0,004^{* *}$ \\
\hline
\end{tabular}

Yleinen käsitys on se, että D-arvo on korkea silloin kun LWR on korkea, sillä lehtisolukko on hyvin sulavaa. Tässä tutkimuksessa elävän lehden sulavuus oli hyvä (D-arvo yli $700 \mathrm{~g} \mathrm{~kg}^{-1} \mathrm{ka}$ ) kaikissa niitoissa, ja sen havaittiin myös olevan suhteellisen vakio yli niittokertojen ja versotyyppien. LWR näytti korreloivan positiivisesti D-arvon kanssa etenkin pääsadossa, kun tuloksia tarkasteltiin yli vuosien. Kun kukin versotyyppi analysoitiin erikseen, VEG-versojen D-arvon ja LWR:n välillä ei havaittu korrelaatiota $(P>0,05)$ pää- tai jälkisadossa. Pääsadossa positiivinen korrelaatio havaittiin ELONG-versojen D-arvon ja LWR välillä $(r=0,46 ; P$ 0,076) ja vahva positiivinen korrelaatio GENversojen D-arvon ja LWR:n välillä $(r=0,86 ; P<0,001)$. Jälkisadossa versotyyppien D-arvon ja LWR:n välistä korrelaatiota ei kuitenkaan havaittu.

Versoihin kiinnittyneen kuolleen solukon määrä saattaa myös joissakin tapauksissa selittää versotyyppien välisiä sulavuuseroja, sillä kuolleen solukon sulavuus oli matala. Versoihin kiinnittyneen kuolleen solukon D-arvo oli pääsadossa keskimäärin $675 \quad \mathrm{~g} \mathrm{~kg}^{-1} \quad \mathrm{ka}$ $\left(\mathrm{SD} \pm 5,0 \mathrm{~g} \mathrm{~kg}^{-1} \mathrm{ka}\right)$ ja jälkisadossa $602 \mathrm{~g} \mathrm{~kg}^{-1} \mathrm{ka}( \pm 21,8)$. Sulavuuksissa ei havaittu merkittäviä eroja versotyyppien tai vuosien välillä. Kiinnittyneen kuolleen solukon pitoisuus oli kuitenkin huomattava vain VEG-versotyypissä, jossa sitä oli $170 \mathrm{~g} \mathrm{~kg}^{-1} \mathrm{ka}( \pm 100)$. ELONG-versoissa kuollutta solukkoa oli $60 \mathrm{~g} \mathrm{~kg}^{-1} \mathrm{ka}( \pm 40)$ ja GEN-versoissa $40 \mathrm{~g} \mathrm{~kg}^{-1} \mathrm{ka}( \pm 20)$. VEG-versotyypin D-arvo laski kiinnittyneen kuolleen solukon pitoisuuden kohotessa vain VEG-versotyypillä, mutta korrelaatio ei ollut vakio eri vuosina.

ELONG- ja GEN-versotyyppien välillä havaitut sulavuuserot näyttävät siten etenkin jälkisadossa olevan enemmän riippuvaisia jostakin muusta tekijästä kuin lehtiosuudesta, kuolleen solukon määrästä tai lehden sulavuudesta. Todennäköisesti näiden versotyyppien korsien sulavuus on erilainen. Tätä hypoteesia tullaan testaamaan tutkimuksen edetessä. Tuloksia voidaan hyödyntää timotein jalostuksessa ja viljelytekniikan kehittämisessä, mikäli tähtäimessä on erityisesti jälkisadon satomäärän ja sulavuuden parantaminen.

\section{Johtopäätökset}

Aikaisemmin tunnettujen vegetatiivisen ja generatiivisen versotyypin lisäksi timoteikasvustosta voitiin erottaa vegetatiivinen elongoituva versotyyppi, jonka osuus kasvustosta oli merkittävä erityisesti jälkisadossa. Lehtien massaosuus selitti hyvin muutoksia pääsadon D-arvossa, mutta ei jälkisadossa. Vegetatiivisten elongoituvien versojen lehtien massaosuus oli jatkuvasti korkeampi kuin generatiivisten versojen. Vegetatiivisten versojen D-arvo pysyi hyvänä koko timoteikasvuston kehittymisen ajan. Pääsatoon kehittyvien vegetatiivisten elongoituvien versojen ja generatiivisten versojen D-arvo näytti olevan samalla tasolla, mutta jälkisadossa vegetatiivinen elongoituva 
versotyyppi oli selvästi sulavampi. Eroja versojen sulavuuseroissa pyritään tulevaisuudessa selittämään versojen aitokorren sulavuuseroilla.

\section{Kirjallisuus}

Bélanger, G., Tremblay, G. F. \& Michaud, R. 2006. The nutritive value of timothy and its improvement through management and breeding. In: Sveinsson T. (ed): Timothy Productivity and Forage Quality. NJF Seminar 384, Akureyri, Iceland, pp. 15-25.

Huhtanen P., Nousiainen J. \& Rinne M. 2006. Recent developments in forage evaluation with special reference to practical applications. Agric. Food Sci. 15:293-323.

Höglind, M., Hanslin, H. M. \& van Oijen, M. 2005. Timothy regrowth, tillering and leaf area dynamics following spring harvest at two growth stages. Field Crops Res. 93, 51-63.

Kuoppala, K., Rinne, M., Nousiainen, J. \& Huhtanen, P. 2007. The effect of cutting time of grass silage in primary growth and regrowth and the interactions between silage quality and concentrate level on milk production of dairy cows. Livest. Sci. In press.

Nousiainen, J., Rinne, M., Hellämäki, M. \& Huhtanen, P. 2003. Prediction of the digestibility of the primary growth of grass silages harvested at different stages of maturity from chemical composition and pepsin-cellulase solubility. Anim. Feed Sci. Tech. 103, 97-111.

Rinne M. 2000. Influence of the timing of the harvest of primary grass growth on herbage quality and subsequent digestion and performance in the ruminant animal. Academic dissertation, University of Helsinki, Department of Animal Science. Publication № 54. 